\title{
Xist localization and function: new insights from multiple levels
}

\author{
Andrea Cerase ${ }^{1 *}$, Greta Pintacuda ${ }^{2}$, Anna Tattermusch $^{2}$ and Philip Avner ${ }^{1,3^{*}}$
}

\begin{abstract}
In female mammals, one of the two $X$ chromosomes in each cell is transcriptionally silenced in order to achieve dosage compensation between the genders in a process called $X$ chromosome inactivation. The master regulator of this process is the long non-coding RNA Xist. During X-inactivation, Xist accumulates in cis on the future inactive $X$ chromosome, triggering a cascade of events that provoke the stable silencing of the entire chromosome, with relatively few genes remaining active. How Xist spreads, what are its binding sites, how it recruits silencing factors and how it induces a specific topological and nuclear organization of the chromatin all remain largely unanswered questions. Recent studies have improved our understanding of Xist localization and the proteins with which it interacts, allowing a reappraisal of ideas about Xist function. We discuss recent advances in our knowledge of Xist-mediated silencing, focusing on Xist spreading, the nuclear organization of the inactive $X$ chromosome, recruitment of the polycomb complex and the role of the nuclear matrix in the process of $X$ chromosome inactivation.
\end{abstract}

\section{Introduction}

$\mathrm{X}$ chromosome inactivation (XCI) is the mechanism that has evolved in eutherian mammals to ensure dosage compensation between $X X$ (female) and $X Y$ (male) individuals. Dosage compensation depends on the efficient silencing of genes on one of the two X chromosomes in each cell of the female early in development. This process is crucially dependent on a specific locus on the $\mathrm{X}$ - the $\mathrm{X}$ inactivation center (XIC) - which includes, among other genetic elements, the Xist gene, which is necessary for the process of XCI [1]. Xist encodes a 17-kb long non-coding RNA (lncRNA) that, despite being capped, spliced and polyadenylated, is retained in the nucleus.

\footnotetext{
*Correspondence: andrea.cerase@embl.it; phil.avner@embl.it

'EMBL Mouse Biology Unit, Monterotondo 00015 (RM), Italy

Full list of author information is available at the end of the article
}

In mouse, $\mathrm{XCI}$ occurs in two different fashions. During early embryogenesis, the paternal $\mathrm{X}$ is preferentially inactivated (imprinted $\mathrm{XCI}$ ). At the blastula stage, in the cells of the inner cell mass, this imprinted XCI is reverted, and each chromosome in such cells has an equal chance to be inactivated (random XCI). Initiation of XCI is associated with the monoallelic upregulation of Xist and its spreading and coating in cis of the presumptive inactive $\mathrm{X}$ (initiation phase of XCI). This triggers a cascade of events, including the acquisition of repressive chromatin modifications, exclusion of RNA polymerase II (Pol II) and removal of active histone marks, histone exchange and DNA methylation. These events act in concert to ensure the stable repression of the entire chromosome and the maintenance of the silent state (maintenance phase of XCI) [2-5].

Although many studies have described various aspects of the underlying XCI mechanism, we are far from having a complete understanding of the process, especially at the molecular level. For example, we currently still do not have definitive answers to questions such as how Xist triggers silencing, how it recruits chromatin remodelers or how the silent state is maintained.

Here, we review recent progress in the field, pointing out the strengths, weaknesses and inconsistencies of recent findings. In particular, we highlight recent evidence indicating that chromosomal topology, nuclear organization, and chromatin accessibility all have key roles in the XCI process [6].

\section{Xist spreading and nuclear organization of the inactive $X$ chromosome}

Two recently published studies have shed light on Xist spreading and localization [7, 8] (and are commented upon elsewhere $[9,10])$. Taking advantage of labeled probes complementary to Xist, pulldowns of Xistassociated chromatin at different stages of XCI were obtained and analyzed by next-generation DNA sequencing [capture hybridization analysis of RNA targets (CHART) and RNA antisense purificationsequencing (RAP-Seq); Box 1]. The studies cover both
() Biomed Central

(C) 2015 Cerase et al. Open Access This article is distributed under the terms of the Creative Commons Attribution 4.0 International License (http://creativecommons.org/licenses/by/4.0/), which permits unrestricted use, distribution, and reproduction in any medium, provided you give appropriate credit to the original author(s) and the source, provide a link to the Creative Commons license, and indicate if changes were made. The Creative Commons Public Domain Dedication waiver (http://creativecommons.org/publicdomain/zero/1.0/) applies to the data made available in this article, unless otherwise stated. 


\section{Box 1 Studying $X$ chromosome inactivation}

\section{Models of $\mathrm{X}$ inactivation}

To study $X$ chromosome inactivation $(X C l)$ and its role in mammalian development, different model systems are used. Differentiating female (XX) embryonic stem cells (ESCS) recapitulate quite closely the early stages of XCl described in the embryo. Female ESCs can be differentiated by using the vitamin A derivative retinoic acid (RA) or by means of removal of leukemia inhibitory factor (LIF; an antidifferentiation agent). Exposure to RA induces transcription of specific target genes triggering differentiation. Culturing cells in the absence of LIF (LIF removal) leads to differentiation of cells and formation of embryoid bodies (EBs). EBs are three-dimensional multicellular aggregates that can have a very non-homogeneous cellular composition. Transgenic ESCs (XX or XY) bearing an inducible Xist-transgene (Xist-Tg) are another commonly used model in $\mathrm{XCI}$ research. These transgenes allow for the tightly controlled expression of Xist RNA. Induction of Xist in this model system has been used for a model of XCI under undifferentiated condition. Mouse embryonic fibroblasts (MEFs) are used as a model of the final step of XCl as they are fully differentiated cells in which $\mathrm{XCl}$ has already occurred.

\section{Culturing of ESCs}

ESCs are generally cultured in high-serum, LIF-containing growth media. Additionally, they are often grown on a layer of fibroblast feeder cells that assist the maintenance of pluripotency. Alternatively, ESCs can be cultured in 2 inhibitory (2i) medium, which contains LIF and two inhibitors, one blocking the mitogen-activated protein kinase signaling molecule Mek and the other inhibiting the glycogen synthase kinase-3 (Gsk3) pathway.

\section{Mapping the localization of ncRNAs}

CHART is a technique - conceptually similar to chromatin immunoprecipitation (ChIP) - that is used to analyze RNA distribution over a given genomic location or on a full genomic scale. In CHART, oligonucleotides complementary to the non-coding RNAs (ncRNAs) of interest are used to specifically enrich for the target RNA-associated DNA (RNA is crosslinked to proteins that are crosslinked to DNA). Through this, RNA associations to chromatin can be mapped to the genome by high-throughput sequencing. RNA antisense purification (RAP) is a variant of CHART. It utilizes tagged RNA probes to capture in vivo targets of ncRNAs. Once the DNA targets are purified, high-throughput sequencing is used to map these onto the genome.

\section{Discovery of ncRNA-protein interactions}

RNA antisense purification with mass spectrometry (RAP-MS) is a technique used to identify proteins directly interacting with ncRNAs in vivo. It exploits in vivo UV crosslinking in order to covalently bind RNA-interacting proteins. Interacting proteins are then recovered by immunoprecipitation (IP) of ncRNA complementary probes in denaturing conditions. This is followed by quantitative mass spectrometry. Chromatin isolation by RNA purification-mass spectrometry (ChIRP-MS) is a method to identify, in vivo, direct and indirect interactions between ncRNAs and proteins. This technique takes advantage of chemical crosslinking to purify ncRNA-neighbouring proteins by IP of ncRNA-complementary probes under non-denaturing conditions. This is followed by mass spectrometry.

\section{Studying chromosome conformations}

3C/4C and $\mathrm{Hi}-\mathrm{C}$ are high-throughput circular chromosome conformation capture methods used to analyze in vivo DNA-DNA interactions. Typically, DNA and interacting proteins are crosslinked with formaldehyde. Through intramolecular ligation cloning, PCR amplification and DNA sequencing, fragments of DNA that were in close three-dimensional proximity are identified. These techniques can be complemented by a variety of super-resolution microscopy techniques such as three-dimensional structured illumination microscopy (3D-SIM) that enhances biological imaging beyond the diffraction limit of wide-field microscopy. In 3D-SIM, the sample is illuminated with spatially structured excitation light. Mathematical analysis of the diffraction patterns allows an increase of the resolution limit to $100 \mathrm{~nm}$. Super-resolution microscopy allows enhanced resolution of the interchromatin, a series of channels between CTs, the perichromatin, a thin layer of de-condensed chromatin around the chromosomal periphery and the chromatin compartment, where relatively more compressed chromatin is present.

\section{Mapping RNA-protein interactions}

A variety of techniques are used to investigate RNA-protein interactions. Conventional RNA immunoprecipitations (RNA-IPS) are relatively nonspecific pulldowns used to verify possible RNA-protein interactions. Crosslinking and immunoprecipitation (CLIP) is one of the most recent techniques developed to unambiguously identify RNA-protein interactions by covalently linking proteins and RNA substrates by UV crosslinking. After immunopurification of these complexes, high-throughput sequencing is used to identify the target RNAs. 
the initiation phase [recapitulated in differentiating female embryonic stem cells (ESCs) and male inducibleXist ESCs], and the maintenance phase of XCI (studied in fully differentiated female fibroblasts; Box 1). Importantly, the different experimental systems used were complementary, compensating for the potential limitations of each system. For instance, in the male inducible-Xist cell lines used by Engreitz and colleagues [7], Xist upregulation can be both more rapid and intense than that occurring at the endogenous Xist locus. It is also possible that early time-points in the inducible systems correspond to relatively late time-points in differentiating female ESC lines [11, 12]. Finally, Xist upregulation in the inducible system is both well synchronized and relatively homogeneous [11], whereas ex vivo differentiation of ESC systems is often both asynchronous and non-homogeneous [6].

The principle result from both papers is the observation that Xist localization is initially restricted to a few discrete genomic locations, before extending more broadly over the entire chromosome. Xist coating starts within silent genedense regions and then proceeds to spread to active genes on the entire presumptive $\mathrm{Xi}$. Both studies $[7,8]$ also confirmed that Xist accumulation at active genes requires the presence of Xist A-repeats, a class of structurally conserved repeats, previously identified as necessary for Xistmediated silencing [12].
The two studies concur to show that, once spread, Xist is associated with gene-rich, open chromatin regions (high-affinity sites), which are enriched for the presence of short interspersed nuclear elements (SINEs) and anti-correlated with the presence of long interspersed nuclear elements (LINEs) and lamin interaction sites $[7,8]$. These observations are in keeping with older cytological evidence suggesting a strong association of Xist localization with G-light bands (gene-rich regions), with gene-poor regions representing, predominantly, Xist low-affinity sites [13, 14] (Fig. 1a).

Strikingly, both papers highlight a strong dependence of Xist localization on the relative positioning of the Xist locus (XIC). Engreitz and colleagues [7] elegantly showed that moving the inducible Xist integration site from its endogenous location to that of the Hprt locus leads to a substantial change in the initial contact sites of Xist accumulation. The new contact sites correlate with the high-throughput chromosome conformation capture (Hi-C) interactions of the new locus [15-17] (Box 1 ). This strongly suggests that Xist exploits genomic proximity and topology in order to spread in cis, rather than depends on the presence of particular consensus sequences, as occurs in Caenorhabditis elegans [18] or in Drosophila [19]. Interestingly, the studies used XIC-centered $\mathrm{HiC}$ datasets obtained from a male

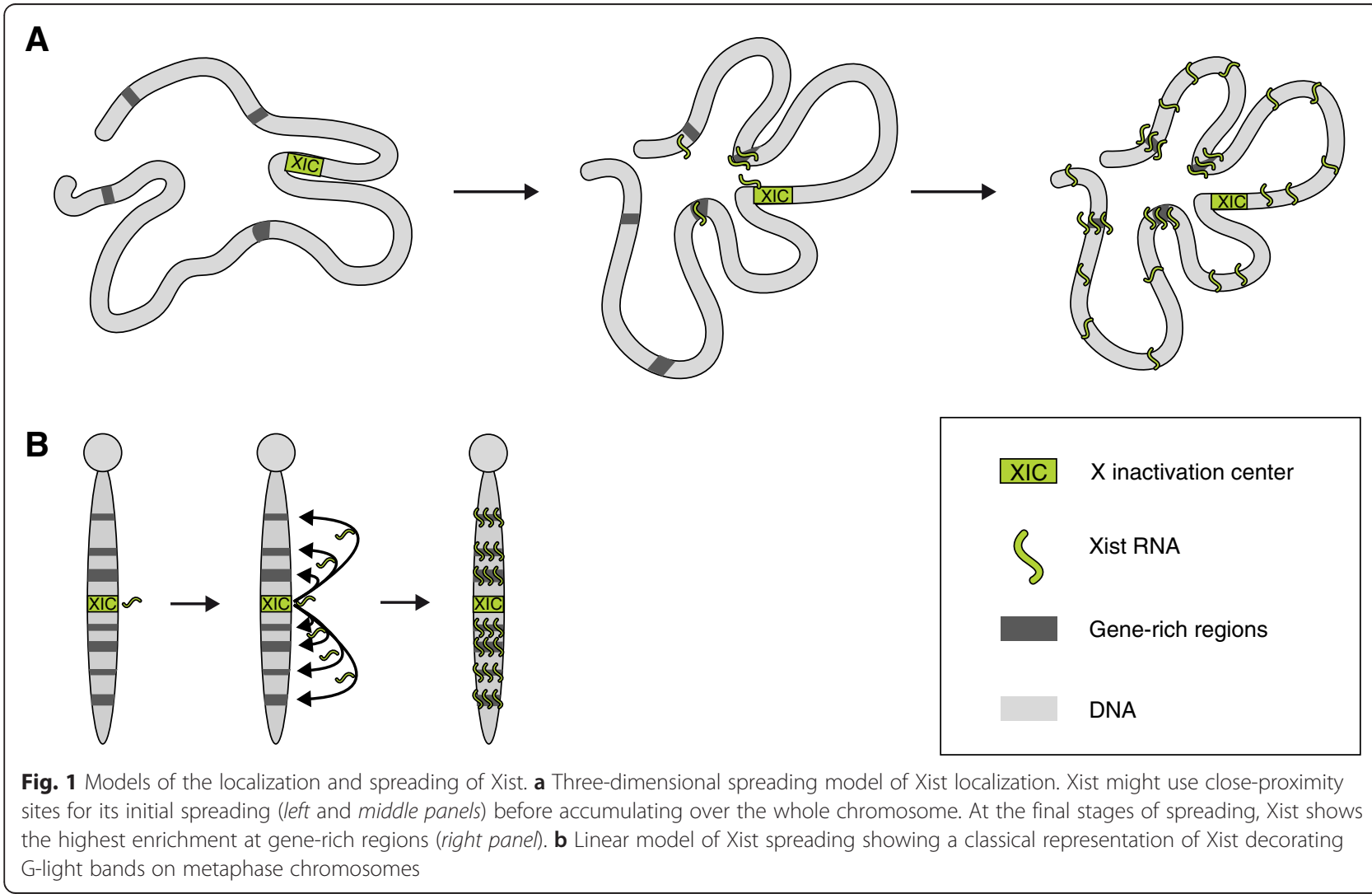


cell line as a reference for identifying regions that are in close proximity, suggesting that the initial steps do not depend on female-specific identifiers [16, 17].

The observation that early localization sites depend on the location of Xist and appear to be exclusively position dependent implies that, at least initially, the first contact sites are not necessarily high-affinity ones. After this first, proximity-driven, accumulation of Xist, Xist then spreads to other target sites. This secondary spreading might be a consequence of the initial contacts, chromosome reorganization or intrinsic site affinity. Given that Xist spreading is likely to be a dynamic process, permissive sites might be those at which Xist is more stably retained [7, 13] (Fig. 1a). This model contrasts strongly with the classic model that proposes linear spreading of Xist along the X chromosome from the XIC $[13,14]$ (Fig. 1b).

Through nuclear architecture and topology studies of the $\mathrm{X}$ chromosome using the circular chromosome conformation capture technique (4C), Splinter and colleagues showed that, upon differentiation of female $\mathrm{ESCs}$, the inactive $\mathrm{X}$ chromosome (Xi) loses the specific interactions between loci that are typical of the active $\mathrm{X}$ chromosome (Xa) [20]. This could be due to Xist binding sites differing in individual differentiated cells [7]. Differential Xist binding in individual cells might result in a loss of specific $4 \mathrm{C}$ signal at the level of the overall cell population upon Xist-induced chromatin remodeling. Noticeably, CHART and Xistcentered $\mathrm{HiC}$ profiles obtained at early time-points in differentiation do show some degree of overlap. However, while Xist profiles obtained by CHART and RAPSeq are broad and diffuse [7,8], the Xist-locus profile generated using $4 \mathrm{C}$ and $\mathrm{HiC}$ is quite sharp, suggesting only a few genomic locations are in close contact with the XIC [20]. This apparent discrepancy could reflect the preference of the latter technique for picking up those genomic sites that interact most frequently or are in closest proximity in most of the cells, while the CHART and RAP-Seq profiles more typically represent an 'average' signal of Xist contact sites within the overall population of cells $[7,8,15,16,20]$. Other differences might be reflections of different experimental protocols - Splinter and colleagues [20], for instance, used a differentiation protocol that enriches for a single specific cell lineage [neuronal precursor cells (NPCs)], whereas Simon et al. [8] and Engreitz et al. [7] used withdrawal of leukemia inhibitory factor (LIF) and differentiation by retinoic acid (RA), respectively. The latter two conditions are known to lead to the differentiation of a heterogeneous mixture of different cell types (Box 1).

Interestingly, Splinter et al. [20] and Minajigi et al. [21], provided evidence for the need for continuous
Xist expression in order to achieve proper folding of the $\mathrm{Xi}$. Indeed, a conditional deletion of Xist was shown to be associated with a reshaping of the topology of the Xi into an Xa-like conformation. Minajigi et al. also suggest a role for the cohesin complex in keeping Xa topologically associated domains (TADs) in place. Such conformation changes might explain the slightly higher rate of reactivation of X-linked genes in Xist-deficient cells observed by the Jaenisch group in the maintenance phase of $\mathrm{XCI}$, which is otherwise thought to be Xist independent [22]. As Xist seems to interact directly with the lamin B receptor (LBR), a protein mediating the interaction between chromatin and lamin B [21, 23], this interaction could be a necessary intermediate in keeping the $\mathrm{Xi}$ in the proximity of the nuclear envelope, where heterochromatin is tethered, thereby reinforcing or stabilizing the Xi conformation and gene silencing [24] (Table 1).

An alternative method that has been applied to studying Xist localization and $\mathrm{Xi}$ topology is fluorescence microscopy. Smeets et al. [25] and Cerase et al. [26] have studied Xist localization by super-resolution three dimensional structured illumination microscopy (3D-SIM) [27], a technique that allows specimen imaging at sub-diffraction resolution (resolution limit $\sim 100 \mathrm{~nm}$; Box 1). Their findings challenge the idea of a broad distribution of Xist along the Xi and suggest that Xist, even when fully spread, might be in contact with only a limited number of genomic sites at any one time. Smeets and colleagues [25] have reported a discrete number of Xist foci (approximately 100 per cell) in fully differentiated and differentiating female ESCs. As each focus might represent multiple Xist molecules, the results are compatible with earlier estimates of the number of Xist molecules, which are in the range of 300 to 1000 per cell $[28,29]$. The apparent disagreement with the results of chromosomewide Xist profiling obtained by RAP and sequencing by capture hybridization analysis of RNA targets (CHART-seq) could reflect differences between the analysis of pooled and single cells. For example, it is clearly possible that Xist localizes to relatively few genomic locations at any one time in a given cell and yet appears as a broad domain when populationbased sequencing approaches are used. An alternative explanation could be that single RNA molecules cannot be detected by RNA fluorescence in situ hybridization [25].

\section{Xist-mediated Polycomb recruitment and gene silencing}

A much-debated aspect of XCI is the link between Xist spreading and recruitment of Polycomb protein. The most widely accepted model predicts a direct recruitment of Polycomb by Xist RNA (Fig. 2a). This 
Table 1 Factors involved in X chromosome inactivation

\begin{tabular}{|c|c|c|}
\hline Factors involved in XCl & Function in the context of $\mathrm{XCl}$ & References \\
\hline \multicolumn{3}{|l|}{ Proteins } \\
\hline PRC2 & $\begin{array}{l}\text { The polycomb repressive complex } 2 \text { (PRC2) is known to be recruited early on the inactive } X(X i) \text { during } \\
\text { differentiation of embryonic stem cells (ESCs) and embryonic development and catalyzes methylation of } \\
\text { histone } \mathrm{H} 3 \text { at } \mathrm{K} 27 \text { on chromatin }\end{array}$ & {$[40,80,81]$} \\
\hline PRC1 & $\begin{array}{l}\text { The activity of polycomb repressive complex } 1 \text { (PRC1) on chromatin reinforces gene silencing by } \\
\text { ubiquitylation of histone } \mathrm{H} 2 \mathrm{~A} \text { at } \mathrm{K} 119 \text { and chromatin compaction. The order of recruitment of PRC2 and } \\
\text { PRC1 to the } \mathrm{Xi} \text { is still a matter of debate }\end{array}$ & {$[82,83]$} \\
\hline Saf-A (HnrnpU) & $\begin{array}{l}\text { The Saf-A (HnrnpU) factor directly binds to Xist and mediates its interaction with chromatin through direct } \\
\text { interaction with SARS/MARS elements }\end{array}$ & $\begin{array}{l}{[21,23,44,} \\
56,58]\end{array}$ \\
\hline SHARP (Spen) & $\begin{array}{l}\text { SHARP (Spen) directly binds to Xist and mediates the functional interaction between Xist and the NCoR } \\
\text { complex }\end{array}$ & {$[21,23,44]$} \\
\hline CTCF & $\begin{array}{l}\text { The CCCTC-binding factor (CTCF) might work as a genomic insulator. In the context of X chromosome in- } \\
\text { activation (XCI), it might serve as a barrier to Xist-induced chromatin reorganization }\end{array}$ & {$[21,67]$} \\
\hline SATB1 & $\begin{array}{l}\text { The special AT-rich sequence-binding protein-1 (SATB1) cellular regulator of higher chromatin } \\
\text { organization has a role in the initiation of XCl. However, its precise role in XCl is not clear }\end{array}$ & {$[59,84]$} \\
\hline YY1 & $\begin{array}{l}\text { Yin-Yang } 1(\mathrm{YY} 1) \text { is a bivalent protein with DNA-binding and RNA-binding motifs. It might have a role in } \\
\text { tethering Xist to chromatin (spreading in cis) as well as a role in the regulation of Xist }\end{array}$ & {$[44,60,85]$} \\
\hline SmchD1 & $\begin{array}{l}\text { The protein structural maintenance of chromosome hinge domain } 1 \text { (SmchD1) has a role in maintaining } \\
\text { a correct pattern of DNA methylation on the Xi during the maintenance phase of } \mathrm{XCl}\end{array}$ & {$[21,86]$} \\
\hline WTAP & $\begin{array}{l}\text { Wilms' tumor-associated protein (WTAP) is a splicing factor and interactor with Xist. It is involved in regu- } \\
\text { lating RNA methylation. It might have a role in the post-transcriptional modification of Xist }\end{array}$ & {$[21,23,44]$} \\
\hline LBR & $\begin{array}{l}\text { The lamin B receptor (LBR) was recently identified as an Xist-binding protein. It is known to localize with } \\
\text { the nuclear lamina and to interact with repressive complexes as well as with lamin B }\end{array}$ & {$[21,23]$} \\
\hline Rbm15 & Rbm15 belongs to the SPEN family of transcriptional repressors and directly binds to Xist RNA & [23] \\
\hline hnRNPK & $\begin{array}{l}\text { Heterogeneous nuclear ribonucleoprotein K (hnRNPK) is an RNA-binding protein that interacts with Xist } \\
\text { and plays a role in the Xist-mediated recruitment of repressive chromatin marks }\end{array}$ & {$[21,44]$} \\
\hline $\begin{array}{l}\text { Oct4, Sox2, Rex1, Nanog, } \\
\text { PRDM14, Klf4 }\end{array}$ & $\begin{array}{l}\text { Pluripotency factors and epigenetic regulators that have been shown to control XCI through the } \\
\text { regulation of Xist and Tsix }\end{array}$ & $\begin{array}{l}{[2,74,87,} \\
88]\end{array}$ \\
\hline Rnf12 & The Rnf12 protein seems to regulate the expression of Xist through degradation of Rex1 & [75] \\
\hline Atrx & $\begin{array}{l}\text { The protein alpha thalassemia/mental retardation syndrome } X \text {-linked (Atrx) is involved in the recruitment } \\
\text { of PRC2 on the inactive X chromosome }\end{array}$ & {$[21,89]$} \\
\hline \multicolumn{3}{|l|}{ nCRNAs } \\
\hline Xist/Tsix & $\begin{array}{l}\text { Xist is the master regulator of } \mathrm{XCl} \text {, and Tsix is its major antagonist. Regulation of the levels of Xist and Tsix } \\
\text { regulates the initiation of } \mathrm{XCl}\end{array}$ & [2] \\
\hline Jpx & The Jpx ncRNA seems to act as an activator of Xist & [2] \\
\hline Ftx & The Ftx ncRNA seems to be an Xist activator & [2] \\
\hline \multicolumn{3}{|l|}{ Genomic elements } \\
\hline LINES & $\begin{array}{l}\text { The LINEs class of genomic repeats colocalize with inactive genes in the } \mathrm{Xi} \text { territory and might have a } \\
\text { role in the establishment and maintenance of } \mathrm{XCl}\end{array}$ & {$[43,90,91]$} \\
\hline SARS/MARS & $\begin{array}{l}\text { Facultative scaffold/matrix attachment regions enriched in open chromatin and gene bodies where Xist } \\
\text { accumulates }\end{array}$ & {$[7,66]$} \\
\hline
\end{tabular}

interaction has been reported to be mediated by the structurally conserved Xist RepA domain, which would interact directly with polycomb repressive complex 2 (PRC2) [30-33]. In agreement with this model, Engreitz et al. [7] and Simon et al. [8] found linear correlations between Xist and PRC2 localization and between Xist and PRC2-mediated tri-methylation of lysine 27 of histone $\mathrm{H} 3$ (H3K27me3). This agrees with previous mapping studies of $\mathrm{PRC} 2$ on the $\mathrm{X}$ chromosome that suggested a broad overall distribution of PRC2 and H3K27me3 [34-36] following accumulation at discrete sites (CpG islands) [36]. Most of the studies supporting a direct recruitment model [30-33] have, however, exploited in vitro biochemical approaches such as band- 


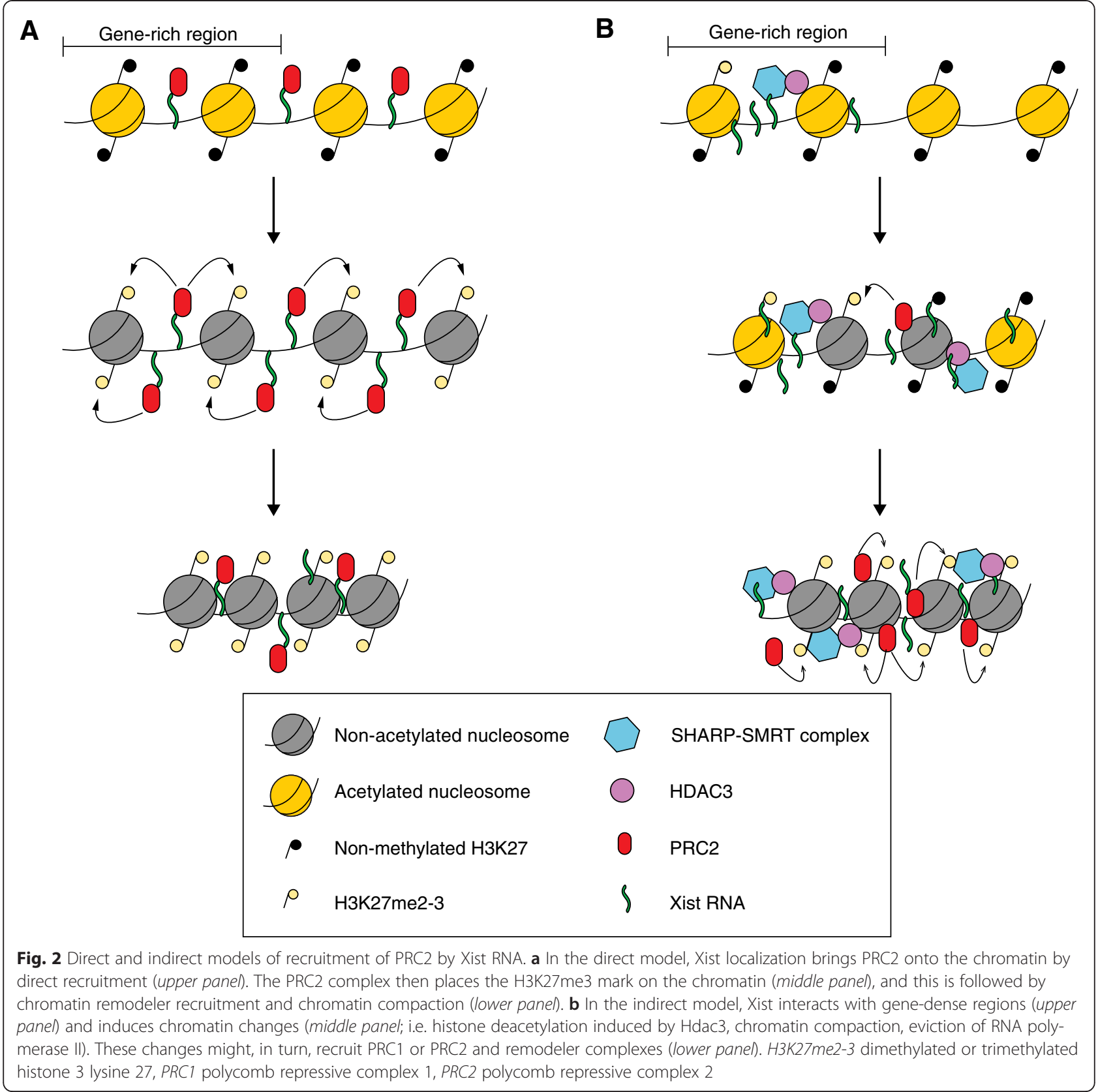

shift assays and RNA immunoprecipitation (RNA-IP) approaches (Box 1). Such techniques are notoriously prone to false-positive results, reflecting non-specific interactions between RNA and proteins.

An almost equally well-represented body of evidence argues against the direct-interaction model. For instance, some studies show that Xist upregulation clearly precedes PRC2 recruitment in early mouse development $[37,38]$, whereas others demonstrate that a RepA deletion mutant version of Xist ( $\triangle$ Arep) is still fully able to recruit PRC2 and H3K27me3 [37-40]. Still-other observations suggest that Xist expression in fully differentiated cells is not sufficient to recruit PRC2. The absence of PRC2 recruitment, upon Xist induction, is not related to the expression level of this complex, as the PRC2 complex is often expressed in such differentiated cells [41].

More-recent observations made by Cerase and colleagues [26] using a 3D-SIM approach showed that the bulk of Xist RNA and PRC2/PRC1 complexes are clearly spatially separated. This finding argues strongly against the direct-interaction model. The study used a mouse male ESC carrying an inducible Xist transgene (Xist-TG) inserted on chromosome 17 and capable of 
Xist upregulation under undifferentiated conditions. Whilst Xist spreading and localization could be influenced by this autosomal context $[25,26,42,43]$ and by the type of undifferentiated culture conditions used, the main findings of this paper have been confirmed using a fully differentiated female cell line [26].

The above study argues that the observed distance between Xist RNA and Polycomb proteins is likely to preclude direct interaction between the PRC complex and Xist (Fig. 2a). This interpretation is supported by results from Smeets et al. [25], who showed that Xist localizes to the inter-chromatin/perichromatin regions (IC/PR), a non-DAPI-dense area that displays poor overlap with H3K27me3 domains (correlating with DAPI-dense chromatin compartments) (Box 1). Both lines of evidence suggest an alternative model not only of how Xist might recruit Polycomb proteins, but also more generally of the role of chromatin remodelers in $\mathrm{X}$ inactivation (Fig. 2b). According to the model, in agreement with Engreitz et al. [7], Xist would initially interact with gene-dense silent regions, possibly partially marked by H3K27me3. It would then induce histone deacetylation, chromatin compaction and the exclusion of Pol II and the basal transcription machinery from nearby active regions [21, 23, 44]. Silenced, compacted chromatin would, in turn, recruit PRC2 and/or chromatin remodelers (indirect model; Fig. 2b) [23, 45, 46]. In accordance with a two-step recruitment model of chromatin factors by Xist, PRC2 initially would only accumulate at approximately 100 to 150 sites before spreading broadly along the X chromosome [36].

Interestingly, Simon and colleagues showed that, when Xist was stripped off the chromatin of female mouse embryonic fibroblasts (MEFs) using complementary locked nucleic acids (LNAs), the kinetics of re-attachment differed from that of the de novo kinetics [8]. This suggests that Xist could also function by priming the chromatin, possibly making it a better substrate for Xist re-spreading after cell division or for recruitment of repressive complexes (for example, by histone deacetylation) $[8,26,39]$. Such an interpretation is, however, in at least partial disagreement with a study from $\mathrm{Ng}$ and colleagues, where Xist re-spreading events were observed to occur with the same kinetics as those seen in the initial round of Xist spreading [47].

Very recently, indirect recruitment of PRC2 by Xist has been confirmed by two independent studies [23, 44], which used biotinylated probes complementary to Xist to pull down Xist-associated proteins for mass spectrometry analysis. While McHugh and colleagues used UV crosslinking conditions coupled with mass spectrometry under denaturing conditions (RAP-MS) [23], Chu and colleagues relied on formaldehyde crosslinking followed by mass spectrometry in non-denaturing conditions (ChIRP-MS) [44) (Box 1). The former technique allows recovery only of direct RNA-protein interactors, whereas the latter also allows recovery of proteins in the same complex or in close proximity that are not interacting directly with Xist [26]. The stringent conditions used by McHugh and colleagues allowed the specific isolation of ten bona fide Xist direct interactors. By contrast, Chu and colleagues found 81 proteins that directly or indirectly associate with Xist. Although Chu et al. reported a possible direct interaction with the PRC1 complex [44], neither study listed members of the PRC2 complex as Xist interactors. McHugh et al. suggest that PRC2 recruitment is a consequence of histone $\mathrm{H} 3$ deacetylation by Hdac3, part of the NCoR repressive complex, and exclusion of Pol II $[23,48]$. They also suggest that the silencing mediator for the retinoic acid receptor and thyroid hormone receptor/nuclear receptor co-repressor (SMRT/NCoR) complex is recruited to the inactivating $\mathrm{X}$ via SMRT- and HDAC-associated repressor complex/Msx2-interacting protein (SHARP/Spen), which itself directly binds to Xist RNA [23, 44] (Fig. 2b). Both knockdown of Hdac3 and of SHARP/Spen have similar negative effects on PRC2 recruitment to the inactive $\mathrm{X}$ and gene silencing. Chu et al. also suggest that heterogeneous nuclear ribonucleoprotein $\mathrm{K}$ (HnrnpK), an heterogeneous nuclear ribonucleoprotein similar to Saf-A, but from which it differs in both binding sites and specificity, might have a direct role in Polycomb recruitment [44].

The results from another very recent proteomics paper [21] contrast with the findings of McHugh et al. and Chu et al. The authors, while using an approach similar to that used by McHugh et al. [22], describe 80 to 250 proteins interacting with Xist at any one time. Among these they were able to identify $\mathrm{RbAp} 46 / \mathrm{RbAp} 48$ proteins as direct interactors with Xist. While these proteins are part of the repressive complex PRC2, it should be noted that they are also part of both the Nurd and Sin3 complexes [49].

Finally, roles have been proposed for Jarid2 and Pcl2, two non-canonical subunits of PRC2 [50], in mediating the recruitment of the PRC2 complex to the $\mathrm{Xi}$ [51, 52]. Knockdown and knockout experiments have shown that PRC2 recruitment on the X is impaired in the absence or reduction of these two PRC2 cofactors, whereas Xist upregulation itself seems to be unaffected. It should be noted that neither study [52, 53] allowed for discrimination between direct versus indirect PRC2 recruitment. Two interesting reviews have addressed the issue of Xist-mediated PRC2 recruitment in detail $[54,55]$.

\section{Nuclear scaffolding and XCI}

Important examples of other putative Xist-interacting proteins that could be involved in Xist spreading and silencing include nuclear scaffold proteins $[25,56-60]$ (Table 1). The nuclear scaffold (also known as nuclear 
matrix) is a stable, proteinaceous structure that remains after treating cell nuclei with high-salt buffers, detergents and nucleases and might provide the framework for chromatin organization. In particular, scaffoldattachment or matrix-attachment regions (SARs or MARs) could be mediating the interaction between DNA and the matrix proteins in a highly regulated fashion.

Fackelmayer and coworkers were the first to describe the enrichment of Saf-A, a nuclear matrix protein, in the $\mathrm{Xi}$ territory [56, 57]. Hasegawa and colleagues [58] subsequently showed that Saf-A is necessary for Xist localization in both neuroblasts and fully differentiated MEFs. They also showed, using UV crosslinking conditions and RNA-IP, that Xist and Saf-A might interact directly [58]. It should be noted that the UV crosslinking experiments performed by Hasegawa and colleagues are less prone to artifacts than are band-shift assays and non-crosslinked-formaldehyde IPs. This is because UV crosslinking between RNA and proteins is only effective over short distances [61] (Box 1). Nevertheless, nucleicacid-protein and protein-protein interactions - involving not only Xist and Saf-A, but also other components - cannot be formally excluded. Smeet and colleagues [25], using a GFP-Saf-A fusion protein, have confirmed the enrichment of Saf-A on the $\mathrm{Xi}$ and have provided additional evidence of a direct interaction between Xist and the Saf-A protein. Using a 3D-SIM approach, they evaluated the average distance between Saf-A and Xist signals. Measured distances fall below the resolution limits of the technique, implying at least some degree of interaction. There is no reason to believe that the use of formaldehyde-fixed cells calls into question the observed interaction as Xist-matrix binding appears relatively stable $[62,63]$. The results of Smeet and colleagues suggest that the Saf-A protein that is enriched on the $\mathrm{Xi}$ could be post-translationally modified (Fig. 3a), an observation in possible agreement with the lack of recognition of Saf-A on the Xi by certain antibodies against SafA [25]. The possibility of post-transcriptional modifications of the scaffold is of interest in the light of results concerning Xist spreading in cis and fuels speculation about the idea that Xist might interact with modified matrix proteins on the presumptive inactive $\mathrm{X}$ and that this would provide the mechanism for restricting Xist RNA spreading to the chromosome from which it was transcribed [64].

Chu et al. [44], McHugh et al. [23] and Minajigi et al. [21] all identified Saf-A as an interactor with Xist, using RAP-MS and ChIRP-MS, and confirmed the role of Saf$\mathrm{A}$ in Xist localization on the inactive $\mathrm{X}$, substantiating the previous findings of Hasegawa and colleagues [58]. Although the authors suggest a direct role for Saf-A in Xist-mediated silencing, as Xist silencing is affected both by a loss of Xist localization and by compaction, other possibilities must be considered [23, 44].

It is tempting to push this model slightly further and hypothesize that Xist interacts directly with modified

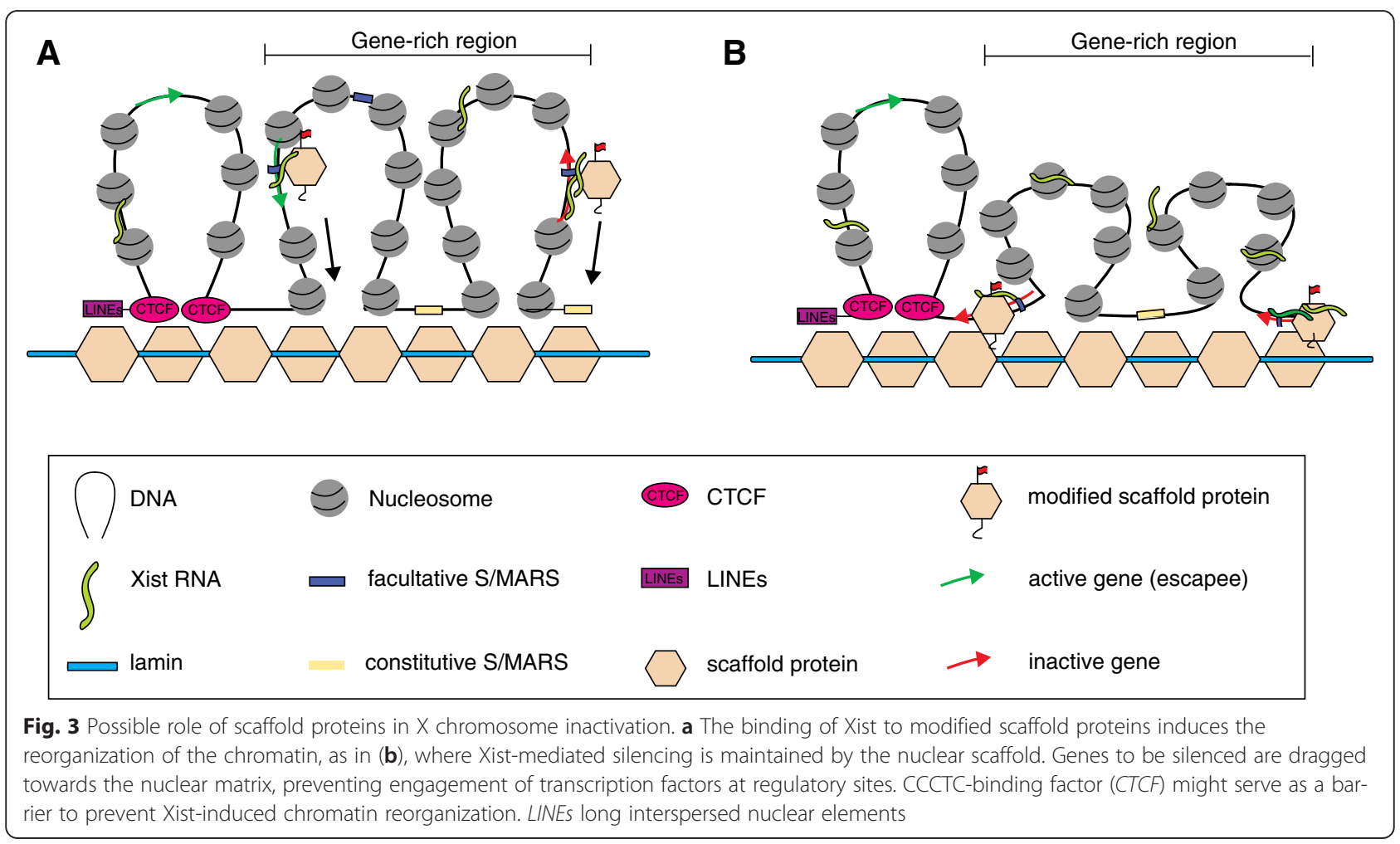


scaffold proteins [63], mediating a chromosome-wide reorganization of the chromosome [40, 65]. Interestingly, facultative scaffold/matrix attachment regions (S/MARs) are enriched in open chromatin regions and in gene bodies, where Xist accumulates [7, 8, 66] (Box 1; Table 1). As Simons et al. and Engreitz et al. have shown that Xist does not accumulate on the gene body of escapee genes, which are genes that avoid being silenced by Xist, and active genes at early stages of XCI, we could further speculate that Xist needs to access the gene bodies to achieve full gene silencing. Under such a model, Xist would accumulate on S/MAR-enriched loci, interacting with posttranslationally modified Saf-A, triggering the relocation of active genes close to repeat-dense regions (for example, LINE-rich and lamin-bound regions) [40, 66], in agreement with the model proposed by Chaumeil and colleagues [40] (Fig. 3a, b). Moving active genes into the proximity of the compacted/repeat-rich region of the Xi would prevent access of the transcription factors to regulatory regions of genes, resulting in silencing [35]. Escapee genes, through a looping of the chromatin outside and away from the repeat-dense region, would be protected from silencing $[40,67]$. CCCTC-binding factor (CTCF) is one factor that has been reported to have a role in the organization of chromosomal domains that efficiently escape XCI [67] (Table 1). The Smeets et al. paper [25], however, challenges the common view of a compacted central area of the $\mathrm{Xi}$, with active genes arranged at the periphery of the $\mathrm{Xi}[40$, 63]. Instead, Smeets and colleagues suggest a honeycombed structure, with the center of the $\mathrm{Xi}$ marked by pockets of reduced compaction, which are permissive for transcription [25]. Differences in the proposed structures likely reflect differences in microscope resolution.

A very recent paper [68] also hints at a possible role of the nuclear matrix in more-general chromatin organization, suggesting that the interaction of noncoding RNAs (ncRNAs) and the nuclear matrix might be a more widespread phenomenon. The authors showed an enrichment of COT-1 RNA in euchromatic regions that directly interact with the nuclear matrix. Such interspersed repeat RNA, which mostly consists of truncated $5^{\prime}$ L1 elements, could serve either to recruit transcription factors or to act as a platform for opening up the chromatin. We are tempted to speculate that Xist competes with C0t-1 RNA for scaffold attachment sites in this context, triggering a release of structural euchromatic RNA, a collapse of chromatin, and triggering silencing [68] (Fig. 4a, b). Smeets and colleagues offer a similar potential explanation for the repressive function of Xist, linked to Xist coating of the $\mathrm{Xi}$, which would prompt a collapse of interchromatin channels that, in turn, impedes access of Pol II and

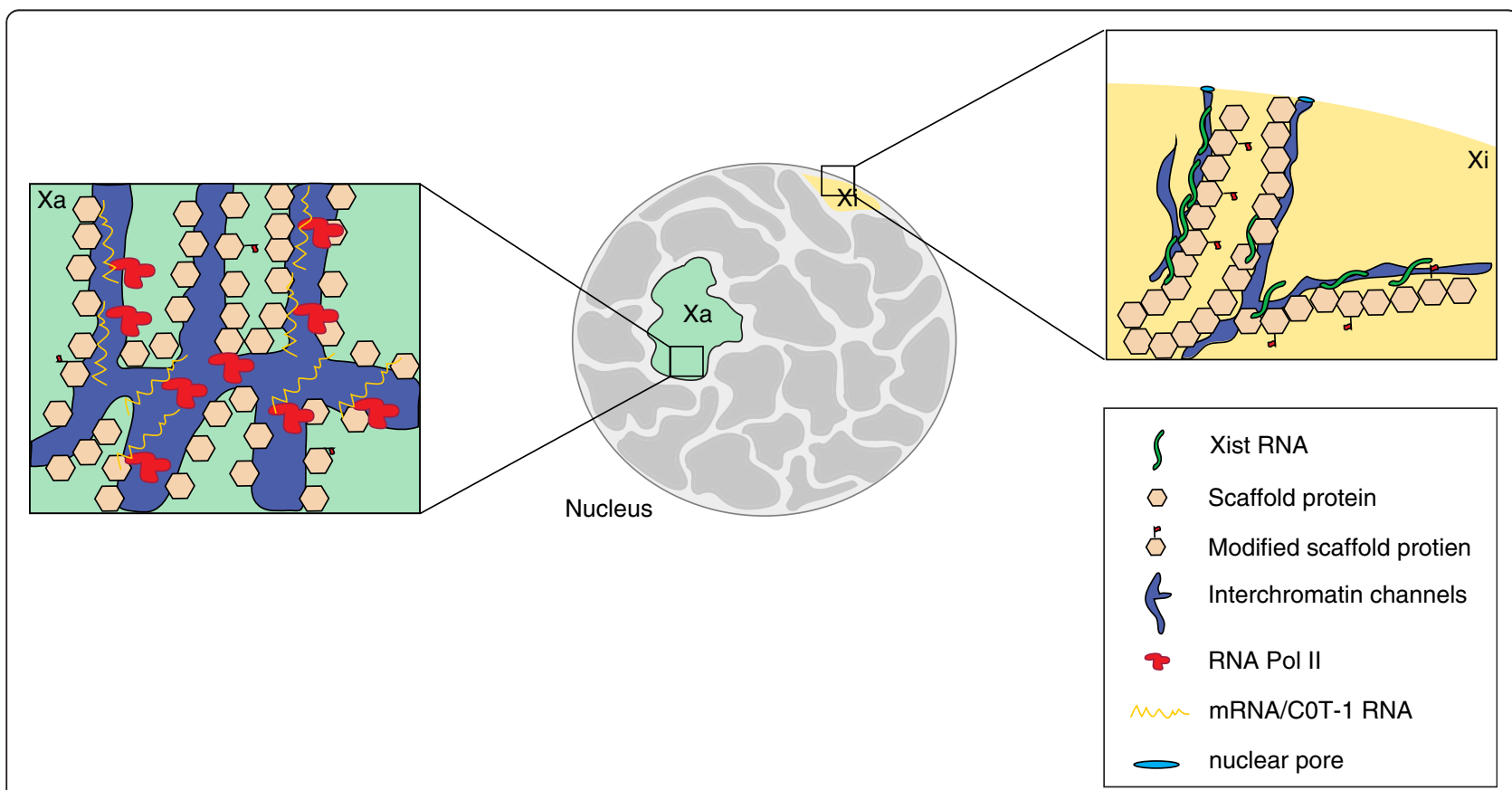

Fig. 4 A speculative model of Xist function. The central part of the diagram shows a nucleus, with the active (Xa) and the inactive (Xi) chromosomal territories highlighted in green and yellow, respectively (gray indicates the chromosomal territories of other chromosomes). Magnified views of the Xi (right) and the Xa (left) territories are shown. The following model is based on the observations of Smeets and colleagues [25]. Coating with Xist RNA might cause a collapse of open chromatin channels, and this, in turn, might block the access of transcription factors and RNA polymerase II (RNA Pol II) to gene-regulatory elements. Alternatively, Xist might compete with C0t-1 RNA, and removal of this class of RNA could, in turn, lead to chromosome compaction [68] 
basal transcription factors to the chromatin. The absence of transcription would, in turn, trigger the recruitment of repressive complexes (for example, PRC2/ PRC1 and DNA methyltransferases), inducing further silencing (Fig. 4a, b). For more information about the role of scaffolding in XCI, we refer the reader to two recent reviews $[69,70]$.

\section{Concluding remarks}

Here, we have discussed several notable advances in the field of Xist biology. The articles under review represent important contributions to our understanding of the mechanism(s) of Xist silencing, especially in relation to four main areas for which there are outstanding gaps in knowledge: (1) Xist spreading; (2) Xi nuclear organization; (3) Polycomb/chromatin remodeler recruitment and gene silencing; and (4) Xist-matrix interactions.

The very recent papers of McHugh et al. [23], Chu et al. [44] and Minajigi et al. [21] have critically shed light on the previously elusive Xist-interacting proteins and how Xist might both establish gene silencing by Hdac3-mediated histone deacetylation and reinforce gene silencing by tethering the inactive $\mathrm{X}$ chromosome to the nuclear periphery through interaction with the lamin $\mathrm{B}$ receptor (LBR) and topoisomerase remodeling of the $\mathrm{Xi}$.

However, many unresolved questions remain. For example, currently available data do not allow determination of whether different Xist splicing variants have a similar function and spreading pattern compared with those of the full-length Xist RNA that is most often exploited experimentally.

Several Xist splice variants have been described, including two major forms [71-73]. More recently a RepA variant of Xist RNA that seems to mimic the full-length version has also been reported [30]. Use of the male ESC Xist-inducible system, which exploits a mature form of Xist, and differentiating female ESC lines, in which Xist transcription is subject to splicing, might therefore not necessarily be completely interchangeable experimentally. A possible way to make the systems more comparable would be to include the relatively small introns of Xist in the inducible constructs. This could be particularly informative in the light of eventual Xist posttranscriptional modifications, which are not necessarily confined to exons.

The regulation of Xist has been shown to be tightly regulated by pluripotency factors $[6,74,75]$, and the pluripotent state of ESCs is known to be highly sensitive to culture conditions. If, as seems likely, silencing initiation and Xist spreading are sensitive to quantitative variations in Xist RNA levels, ex vivo culture conditions might also crucially impact inactivation parameters. For example, ESCs grown in 2 inhibitor (2i) medium culture conditions are known to be closer to the 'ground zero' state of pluripotency [76], to have a more homogeneous composition [76] and to show different transcriptional profiles compared with those of cells grown under conventional LIF and serum conditions [77-79]. Both differentiation and upregulation of XIC lncRNAs clearly occur much faster using such $2 \mathrm{i}$ cultured cells, but whether the underlying mechanisms differ or remain unchanged still needs to be clarified. Only through standardization of ESC culturing (for example, by consistent use of $2 \mathrm{i}$ culturing conditions) and differentiation protocols (for example, using NPC differentiation) will direct comparison of data obtained in different experiments be possible.

Finally, given that the initial Xist spreading is likely to vary between individual cells, validation at the single-cell level, including single-cell RAP/CHART experiments, will be key towards obtaining a more thorough characterization and a better knowledge of Xist early dynamics. Such approaches would be expected to facilitate the identification of causal correlations between possible chromatin states and specific modifications of Xist binding sites.

\section{Abbreviations}

2C: two-cell embryonic stage; 2i medium: 2 inhibitor medium; 3D-SIM: three dimensional structured illumination microscopy; 4C: circular chromosome conformation capture; Atrx: alpha thalassemia/mental retardation syndrome X-linked; CHART: capture hybridization analysis of RNA targets; ChIRPMS: chromatin isolation by RNA purification-mass spectrometry; CLIP: crosslinking and immunoprecipitation; CTCF: CCCTC-binding factor; DAPI: 4',6-diamidino-2-phenylindole; EB: embryoid body; ESC: embryonic stem cell; Hi-C: high-throughput chromosome conformation capture; HnrnpK: heterogeneous nuclear ribonucleoprotein K; H3K27me3: histone 3 lysine 27 trimethylation; IP: immunoprecipitation; IncRNA: long non-coding RNA; LBR: lamin B receptor; LIF: leukemia inhibitory factor; LINE: long interspersed nuclear element; MEF: mouse embryonic fibroblast; ncRNA: noncoding RNA; NPC: neuronal precursor cell; Pol II: RNA polymerase II; RA: retinoic acid; RAP-Seq: RNA antisense purification-sequencing; RAPMS: RNA antisense purification-mass spectrometry; RepA: repeat A region of Xist RNA; RNA-IP: RNA immunoprecipitation; Pol II: RNA polymerase II; PRC1/ PRC2: polycomb repressive complex 1/polycomb repressive complex 2; SAFA (hnrnpU): scaffold attachment factor A (heterogeneous ribonucleoprotein U); SatB1: special AT-rich sequence-binding protein-1; SINE: short interspersed nuclear element; SmchD1: structural maintenance of chromosome hinge domain 1; SHARP/Spen: SMRT- and HDAC-associated repressor complex/Msx2-interacting protein; S/MAR: scaffold/matrix attachment region; SMRT/NCoR: silencing mediator for retinoic acid receptor and thyroid hormone receptor/nuclear receptor co-repressor; TAD: topologically associated domain; WTAP: Wilms' tumor-associated protein; Xa: active $X$ chromosome; $X \mathrm{Cl}$ : $X$ chromosome inactivation; $X i$ inactive $X$ chromosome; XIC: $X$ inactivation center; Xist: inactive $X$-specific transcript; Xist-TG: Xist transgene; YY1: Yin-Yang 1.

\section{Competing interests}

The authors declare that they have no competing interests.

Authors' contributions

PA and AC conceived this project. PA, AC, GP and AT designed the figures and wrote the paper. 


\section{Acknowledgments}

We apologize to all those colleagues whose work could not be discussed and cited in this review owing to space limitations. We thank, in particular, Kristina Cavalletti-Havas, Sara Buonomo, Christophe Lancrin and members of the Avner group for critical reading of the manuscript. PA and AC were funded by EMBL grant to PA, GP was funded by a Welcome Trust Grant, and AT was funded by an SDW fellowship and by MRC grant number 1036324 .

\section{Author details}

${ }^{1}$ EMBL Mouse Biology Unit, Monterotondo 00015 (RM), Italy. ${ }^{2}$ Department of Biochemistry, University of Oxford, Oxford OX1 3QU, UK. ${ }^{3}$ Institut Pasteur, Unite de Genetique Moleculaire Murine, CNRS, URA2578 Paris, France.

\section{Published online: 15 August 2015}

\section{References}

1. Penny GD, Kay GF, Sheardown SA, Rastan S, Brockdorff N. Requirement for Xist in X chromosome inactivation. Nature. 1996;379:131-7.

2. Augui $S$, Nora EP, Heard E. Regulation of X-chromosome inactivation by the X-inactivation centre. Nat Rev Genet. 2011;12:429-42.

3. Lee JT, Bartolomei MS. X-inactivation, imprinting, and long noncoding RNAs in health and disease. Cell. 2013;152:1308-23.

4. Morey C, Avner P. The demoiselle of X-inactivation: 50 years old and as trendy and mesmerising as ever. PLoS Genet. 2011;7:e1002212.

5. Matarazzo MR, Cerase A, D'Esposito M. Building up the inactive $X$ chromosome. Biol Cell. 2008;100:63-70.

6. Pollex T, Heard E. Recent advances in X-chromosome inactivation research. Curr Opin Cell Biol. 2012;24:825-32.

7. Engreitz JM, Pandya-Jones A, McDonel P, Shishkin A, Sirokman K, Surka C, et al. The Xist IncRNA exploits three-dimensional genome architecture to spread across the X chromosome. Science. 2013;341:1237973.

8. Simon MD, Pinter SF, Fang R, Sarma K, Rutenberg-Schoenberg M, Bowman SK, et al. High-resolution Xist binding maps reveal two-step spreading during X-chromosome inactivation. Nature. 2013;504:465-9.

9. Leung KN, Panning B. X-inactivation: Xist RNA uses chromosome contacts to coat the X. Curr Biol. 2014;24:R80-2.

10. Dimond A, Fraser P. Molecular biology. Long noncoding RNAs Xist in three dimensions. Science. 2013;341:720-1.

11. Wutz A, Jaenisch R. A shift from reversible to irreversible $X$ inactivation is triggered during ES cell differentiation. Mol Cell. 2000;5:695-705.

12. Wutz A, Rasmussen TP, Jaenisch R. Chromosomal silencing and localization are mediated by different domains of Xist RNA. Nat Genet. 2002;30:167-74.

13. Duthie SM, Nesterova TB, Formstone EJ, Keohane AM, Turner BM, Zakian SM, et al. Xist RNA exhibits a banded localization on the inactive $X$ chromosome and is excluded from autosomal material in cis. Hum Mol Genet. 1999;8:195-204.

14. Smith KP, Byron M, Clemson CM, Lawrence JB. Ubiquitinated proteins including $\mathrm{UH} 2 \mathrm{~A}$ on the human and mouse inactive $\mathrm{X}$ chromosome: enrichment in gene rich bands. Chromosoma. 2004;113:324-35.

15. Nora EP, Lajoie BR, Schulz EG, Giorgetti L, Okamoto I, Servant N, et al. Spatial partitioning of the regulatory landscape of the $\mathrm{X}$-inactivation centre. Nature. 2012:485:381-5.

16. Dixon JR, Selvaraj S, Yue F, Kim A, Li Y, Shen Y, et al. Topological domains in mammalian genomes identified by analysis of chromatin interactions. Nature. 2012;485:376-80.

17. Lieberman-Aiden E, van Berkum NL, Williams L, Imakaev M, Ragoczy T, Telling $A$, et al. Comprehensive mapping of long-range interactions reveals folding principles of the human genome. Science. 2009;326:289-93.

18. Csankovszki G, McDonel P, Meyer BJ. Recruitment and spreading of the $C$. elegans dosage compensation complex along $X$ chromosomes. Science. 2004;303:1182-5

19. Straub T, Grimaud C, Gilfillan GD, Mitterweger A, Becker PB. The chromosomal high-affinity binding sites for the Drosophila dosage compensation complex. PLoS Genet. 2008;4, e1000302.

20. Splinter E, de Wit E, Nora EP, Klous P, van de Werken HJ, Zhu Y, et al. The inactive $X$ chromosome adopts a unique three-dimensional conformation that is dependent on Xist RNA. Genes Dev. 2011;25:1371-83.

21. Minajigi A, Froberg JE, Wei C, Sunwoo H, Kesner B, Colognori D, et al. A comprehensive Xist interactome reveals cohesin repulsion and an RNAdirected chromosome conformation. Science. 2015;349:6245.
22. Csankovszki G, Nagy A, Jaenisch R. Synergism of Xist RNA, DNA methylation, and histone hypoacetylation in maintaining $X$ chromosome inactivation. J Cell Biol. 2001;153:773-84

23. McHugh CA, Chen CK, Chow A, Surka CF, Tran C, McDonel P, et al. The Xist IncRNA interacts directly with SHARP to silence transcription through HDAC3. Nature. 2015;521:232-6.

24. Zhang LF, Huynh KD, Lee JT. Perinucleolar targeting of the inactive $X$ during $S$ phase: evidence for a role in the maintenance of silencing. Cell. 2007;129:693-706.

25. Smeets D, Markaki Y, Schmid VJ, Kraus F, Tattermusch A, Cerase A, et al. Three-dimensional super-resolution microscopy of the inactive $X$ chromosome territory reveals a collapse of its active nuclear compartment harboring distinct Xist RNA foci. Epigenetics Chromatin. 2014;7:8.

26. Cerase A, Smeets D, Tang YA, Gdula M, Kraus F, Spivakov M, et al. Spatial separation of Xist RNA and polycomb proteins revealed by superresolution microscopy. Proc Natl Acad Sci U S A. 2014;111:2235-40.

27. Schermelleh L, Carlton PM, Haase S, Shao L, Winoto L, Kner P, et al. Subdiffraction multicolor imaging of the nuclear periphery with 3D structured illumination microscopy. Science. 2008;320:1332-6.

28. Buzin CH, Mann JR, Singer-Sam J. Quantitative RT-PCR assays show Xist RNA levels are low in mouse female adult tissue, embryos and embryoid bodies. Development. 1994;120:3529-36.

29. Sun BK, Deaton AM, Lee JT. A transient heterochromatic state in Xist preempts $X$ inactivation choice without RNA stabilization. Mol Cell. 2006;21:617-28.

30. Zhao J, Sun BK, Erwin JA, Song JJ, Lee JT. Polycomb proteins targeted by a short repeat RNA to the mouse X chromosome. Science. 2008;322:750-6.

31. Kaneko S, Li G, Son J, Xu CF, Margueron R, Neubert TA, et al. Phosphorylation of the PRC2 component Ezh2 is cell cycle-regulated and up-regulates its binding to ncRNA. Genes Dev. 2010;24:2615-20.

32. Maenner S, Blaud M, Fouillen L, Savoye A, Marchand V, Dubois A, et al. 2-D structure of the A region of Xist RNA and its implication for PRC2 association. PLoS Biol. 2010;8:e1000276.

33. Kanhere A, Viiri K, Araújo CC, Rasaiyaah J, Bouwman RD, Whyte WA, et al. Short RNAs are transcribed from repressed polycomb target genes and interact with polycomb repressive complex-2. Mol Cell. 2010;38:675-88.

34. Marks H, Chow JC, Denissov S, Françoijs KJ, Brockdorff N, Heard E, et al. High-resolution analysis of epigenetic changes associated with $X$ inactivation. Genome Res. 2009;19:1361-73.

35. Calabrese JM, Sun W, Song L, Mugford JW, Williams L, Yee D, et al. Sitespecific silencing of regulatory elements as a mechanism of $X$ inactivation. Cell. 2012;151:951-63.

36. Pinter SF, Sadreyev RI, Yildirim E, Jeon Y, Ohsumi TK, Borowsky M, et al. Spreading of $X$ chromosome inactivation via a hierarchy of defined Polycomb stations. Genome Res. 2012;22:1864-76.

37. Okamoto I, Otte AP, Allis CD, Reinberg D, Heard E. Epigenetic dynamics of imprinted $X$ inactivation during early mouse development. Science. 2004;303:644-9.

38. Mak W, Nesterova TB, de Napoles M, Appanah R, Yamanaka S, Otte AP, et al. Reactivation of the paternal $X$ chromosome in early mouse embryos. Science. 2004;303:666-9.

39. Kohlmaier A, Savarese F, Lachner M, Martens J, Jenuwein T, Wutz A. A chromosomal memory triggered by Xist regulates histone methylation in $\mathrm{X}$ inactivation. PLOS Biol. 2004;2, E171.

40. Chaumeil J, Le Baccon P, Wutz A, Heard E. A novel role for Xist RNA in the formation of a repressive nuclear compartment into which genes are recruited when silenced. Genes Dev. 2006;20:2223-37.

41. Savarese F, Flahndorfer K, Jaenisch R, Busslinger M, Wutz A. Hematopoietic precursor cells transiently reestablish permissiveness for $\mathrm{X}$ inactivation. $\mathrm{Mol}$ Cell Biol. 2006;26:7167-77.

42. Popova BC, Tada T, Takagi N, Brockdorff N, Nesterova TB. Attenuated spread of X-inactivation in an X;autosome translocation. Proc Natl Acad Sci U S A. 2006;103:7706-11.

43. Tang YA, Huntley D, Montana G, Cerase A, Nesterova TB, Brockdorff N. Efficiency of Xist-mediated silencing on autosomes is linked to chromosomal domain organisation. Epigenetics Chromatin. 2010;3:10.

44. Chu C, Zhang QC, da Rocha ST, Flynn RA, Bharadwaj M, Calabrese JM, et al. Systematic discovery of Xist RNA binding proteins. Cell. 2015;161:404-16.

45. Yuan W, Wu T, Fu H, Dai C, Wu H, Liu N, et al. Dense chromatin activates Polycomb repressive complex 2 to regulate $\mathrm{H} 3$ lysine 27 methylation. Science. 2012;337:971-5. 
46. Riising EM, Comet I, Leblanc B, Wu X, Johansen JV, Helin K. Gene silencing triggers polycomb repressive complex 2 recruitment to $\mathrm{CpG}$ islands genome wide. Mol Cell. 2014;55:347-60.

47. Ng K, Daigle N, Bancaud A, Ohhata T, Humphreys P, Walker R, et al. A system for imaging the regulatory noncoding Xist RNA in living mouse embryonic stem cells. Mol Biol Cell. 2011;22:2634-45.

48. Perissi V, Jepsen K, Glass CK, Rosenfeld MG. Deconstructing repression: evolving models of co-repressor action. Nat Rev Genet. 2010;11:109-23.

49. Adcock IM, Ford P, Ito K, Barnes PJ. Epigenetics and airways disease. Respir Res. 2006;7:21.

50. Schwartz YB, Pirrotta V. A new world of Polycombs: unexpected partnerships and emerging functions. Nat Rev Genet. 2013;14:853-64.

51. Casanova M, Preissner T, Cerase A, Poot R, Yamada D, Li X, et al. Polycomblike 2 facilitates the recruitment of PRC2 Polycomb group complexes to the inactive $\mathrm{X}$ chromosome and to target loci in embryonic stem cells. Development. 2011;138:1471-82.

52. da Rocha ST, Boeva V, Escamilla-Del-Arenal M, Ancelin K, Granier C, Matias $\mathrm{NR}$, et al. Jarid2 is implicated in the initial Xist-induced targeting of PRC2 to the inactive X chromosome. Mol Cell. 2014;53:301-16.

53. Kaneko S, Bonasio R, Saldaña-Meyer R, Yoshida T, Son J, Nishino K, et al. Interactions between JARID2 and noncoding RNAs regulate PRC2 recruitment to chromatin. Mol Cell. 2014;53:290-300.

54. Brockdorff N. Chromosome silencing mechanisms in X-chromosome inactivation: unknown unknowns. Development. 2011;138:5057-65.

55. Brockdorff N. Noncoding RNA, and Polycomb recruitment. RNA 2013;19:429-42.

56. Helbig R, Fackelmayer FO. Scaffold attachment factor A (SAF-A) is concentrated in inactive $X$ chromosome territories through its RGG domain. Chromosoma. 2003;12:173-82.

57. Fackelmayer FO. A stable proteinaceous structure in the territory of inactive X chromosomes. J Biol Chem. 2005;280:1720-3.

58. Hasegawa Y, Brockdorff N, Kawano S, Tsutui K, Tsutui K, Nakagawa S. The matrix protein hnRNP $U$ is required for chromosomal localization of Xist RNA. Dev Cell. 2010;19:469-76.

59. Agrelo R, Souabni A, Novatchkova M, Haslinger C, Leeb M. Komnenovic, et al. SATB1 defines the developmental context for gene silencing by Xist in lymphoma and embryonic cells. Dev Cell. 2009;16:507-16.

60. Jeon $Y$, Lee JT. YY1 tethers Xist RNA to the inactive $X$ nucleation center. Cell. 2011;146:119-33.

61. Ascano M, Hafner M, Cekan P, Gerstberger $\mathrm{S}$, Tuschl T. Identification of RNAprotein interaction networks using PAR-CLIP. Wiley Interdiscip Rev RNA. 2012;3:159-77.

62. Schmiedeberg L, Skene P, Deaton A, Bird A. A temporal threshold for formaldehyde crosslinking and fixation. PloS One. 2009:4:e4636.

63. Clemson CM, McNeil JA, Willard HF, Lawrence JB. XIST RNA paints the inactive $X$ chromosome at interphase: evidence for a novel RNA involved in nuclear/chromosome structure. J Cell Biol. 1996;132:259-75.

64. Hall LL, Byron M, Pageau G, Lawrence JB. AURKB-mediated effects on chromatin regulate binding versus release of XIST RNA to the inactive chromosome. J Cell Biol. 2009;186:491-507.

65. Clemson CM, Hall LL, Byron M, McNeil J, Lawrence JB. The X chromosome is organized into a gene-rich outer rim and an internal core containing silenced nongenic sequences. Proc Natl Acad Sci U S A. 2006;103:7688-93.

66. Gluch A, Vidakovic M, Bode J. Scaffold/matrix attachment regions (S/MARs): relevance for disease and therapy. Handb Exp Pharmacol. 2008;186:67-103.

67. Filippova GN, Cheng MK, Moore JM, Truong JP, Hu YJ, Nguyen DK, et al. Boundaries between chromosomal domains of $X$ inactivation and escape bind CTCF and lack CPG methylation during early development. Dev Cell. 2005;8:31-42.

68. Hall LL, Carone DM, Gomez AV, Kolpa HJ, Byron M, Mehta N, et al. Stable COT-1 repeat RNA is abundant and is associated with euchromatic interphase chromosomes. Cell. 2014;156:907-19.

69. Tattermusch A, Brockdorff N. A scaffold for X chromosome inactivation. Hum Genet. 2011;130:247-53.

70. Hasegawa $Y$, Nakagawa $S$. Revisiting the function of nuclear scaffold/matrix binding proteins in X chromosome inactivation. RNA Biol. 2011;8:735-9.

71. Royce-Tolland ME et al. The A-repeat links ASF/SF2-dependent Xist RNA processing with random choice during $X$ inactivation. Nat Struct Mol Biol. 2010;17:948-54.
72. Ciaudo C, Bourdet A, Cohen-Tannoudji M, Dietz HC, Rougeulle C, Avner P. Nuclear mRNA degradation pathway(s) are implicated in Xist regulation and X chromosome inactivation. PLoS Genet. 2006;2:e94.

73. Memili E, Hong YK, Kim DH, Ontiveros SD, Strauss WM. Murine Xist RNA isoforms are different at their $3^{\prime}$ ends: a role for differential polyadenylation. Gene. 2001;266:131-7.

74. Navarro P, Chambers I, Karwacki-Neisius V, Chureau C, Morey C, Rougeulle C, et al. Molecular coupling of Xist regulation and pluripotency. Science. 2008;321:1693-5

75. Gontan C, Achame EM, Demmers J, Barakat TS, Rentmeester E, van IJcken W, et al. RNF12 initiates X-chromosome inactivation by targeting REX1 for degradation. Nature. 2012;485:386-90.

76. Marks H, Kalkan T, Menafra R, Denissov S, Jones K, Hofemeister H, et al. The transcriptional and epigenomic foundations of ground state pluripotency. Cell. 2012;149:590-604

77. Silva J, Nichols J, Theunissen TW, Guo G, van Oosten AL, Barrandon O, et al. Nanog is the gateway to the pluripotent ground state. Cell. 2009:138:722-37.

78. Ying QL, Wray J, Nichols J, Batlle-Morera L, Doble B, Woodgett J, et al. The ground state of embryonic stem cell self-renewal. Nature. 2008;453:519-23.

79. Silva J, Barrandon O, Nichols J, Kawaguchi J, Theunissen TW, Smith A. Promotion of reprogramming to ground state pluripotency by signal inhibition. PLoS Biol. 2008;6:e253.

80. Plath K, Fang J, Mlynarczyk-Evans SK, Cao R, Worringer KA, Wang H, et al. Role of histone $\mathrm{H} 3$ lysine 27 methylation in $\mathrm{X}$ inactivation. Science. 2003;300:131-5.

81. Silva J, Mak W, Zvetkova I, Appanah R, Nesterova TB, Webster Z, et al. Establishment of histone $\mathrm{H} 3$ methylation on the inactive $X$ chromosome requires transient recruitment of Eed-Enx1 polycomb group complexes. Dev Cell. 2003:4:481-95.

82. Blackledge NP, Farcas AM, Kondo T, King HW, McGouran JF, Hanssen LL, et al. Variant PRC1 complex-dependent H2A ubiquitylation drives PRC2 recruitment and polycomb domain formation. Cell. 2014;157:1445-59.

83. Schoeftner S, Sengupta AK, Kubicek S, Mechtler K, Spahn L, Koseki H, et al. Recruitment of PRC1 function at the initiation of $X$ inactivation independent of PRC2 and silencing. EMBO J. 2006:25:3110-22.

84. Nechanitzky R, Davila A, Savarese F, Fietze S, Grosschedl R. Satb1 and Satb2 are dispensable for $\mathrm{X}$ chromosome inactivation in mice. Dev Cell. 2012;23:866-71.

85. Makhlouf M, Ouimette JF, Oldfield A, Navarro P, Neuillet D, Rougeulle C. A prominent and conserved role for $\mathrm{Y} Y 1$ in Xist transcriptional activation. Nat Commun. 2014:5:4878

86. Gendrel AV, Apedaile A, Coker H, Termanis A, Zvetkova I, Godwin J, et al. Smchd1-dependent and -independent pathways determine developmental dynamics of $\mathrm{CpG}$ island methylation on the inactive $X$ chromosome. Dev Cell. 2012;23:265-79

87. Navarro P, Oldfield A, Legoupi J, Festuccia N, Dubois A, Attia M, et al. Molecular coupling of Tsix regulation and pluripotency. Nature. 2010;468:457-60.

88. Payer B, Rosenberg M, Yamaji M, Yabuta Y, Koyanagi-Aoi M, Hayashi K, et al. Tsix RNA and the germline factor, PRDM14, link $X$ reactivation and stem cell reprogramming. Mol Cell. 2013;52:805-18.

89. Sarma K, Cifuentes-Rojas C, Ergun A, Del Rosario A, Jeon Y, White F, et al. ATRX directs binding of PRC2 to Xist RNA and Polycomb targets. Cell. 2014;159:869-83.

90. Bailey JA, Carrel L, Chakravarti A, Eichler EE. Molecular evidence for a relationship between LINE-1 elements and X chromosome inactivation: the Lyon repeat hypothesis. Proc Natl Acad Sci U S A. 2000;97:6634-9.

91. Chow JC, Ciaudo C, Fazzari MJ, Mise N, Servant N, Glass JL, et al. LINE-1 activity in facultative heterochromatin formation during $X$ chromosome inactivation. Cell. 2010;141:956-69. 